\title{
Modeling, Design, and Life Performance Prediction for Energy Production from Geothermal Reservoirs
}

\author{
Grant DE-FG07-97ID13533 \\ First Quarter Progress Report, August 15, 1997 \\ Daniel Swenson \\ Mechanical Engineering Department \\ Kansas State University \\ Manhattan, KS 66506 \\ (785)532-2320, swenson@ksu.edu
}

\section{SUMMARY:}

The objective of this project is to both transfer existing Hot Dry Rock two-dimensional fractured reservoir analysis capability to the geothermal industry and to extend the analysis concepts to three dimensions. The project start date was May 22, 1997 and it runs through May 21, 1998. This is the first quarterly progress report.

In this quarter, the primary focus has been on interaction with industry, development of the Geocrack3D model, and maintenance of Geocrack2D. It is important to emphasize that our modeling is complementary to current industry modeling, in that we focus on flow in fractured rock and on the coupled effect of thermal cooling, while a primary focus of current modeling technology is multi-phase flow.

\section{INDUSTRY INTERACTION:}

\section{Visit to Unocal Corporation}

We visited Unocal Corporation (Santa Rosa, CA) on July 9 to meet with Tim Anderson, Ken Williamson, Julie Sheneta, and Glenn Melosh of Unocal Geothermal of Indonesia. Ron Schroeder (consultant) and Bob DuTeaux also participated.

The goal of the meeting was to provide Unocal with a better understanding of our current Geocrack2D model and to discuss how it could be applied to problems of interest to Unocal. The meeting was initiated by Glenn Melosh, who was interested in using Geocrack2D to help understand the significance of microseismic signals observed in Unocal geothermal fields. 


\section{DISCLAMIER}

Portions of this document may be illegible in electronic image products. Images are produced from the best available original docoment. 
Some questions include the cause of seismicity (pressure opening or thermal stress relief) and whether the signals indicate significant flow. We also presented our goals for 3D model development, especially the rigorous approach to geometric description and the interactive user interface.

The meeting lasted from about 10:00 a.m. until 3:00 p.m. I think I can honestly say that all participants felt the meeting was very informative. Unocal has indicated initial interest in further pursuing modeling of cold water injection and mesh generation (3D). We are in active discussion with Tim Anderson at Unocal to better define potential collaboration and possible proposals.

\section{Visit to Oxbow Power Services}

On July 10, we visited Oxbow Power Services and met with Dick Benoit to discuss Geocrack2D and our future goals. The intent of this meeting was to present a concept for collaborative work between Kansas State University, the Energy and Geoscience Institute (EGI) at the University of Utah, and Oxbow Power Services.

At this point, we are proceeding with a joint proposal in response to the present DOE geothermal solicitation that closes September 30. A draft proposal has been completed to develop modeling capability focusing on flow in fractured reservoirs. We will apply the 3D model to simulate tracer and fluid flow in the Dixie Valley reservoir. Kansas State University will be responsible for model development, Peter Rose and Denise Apperson at EGI will provide tracer data and use the Geocrack3D model, and Oxbow will provide additional data and act as a reality check on the project, both with respect to modeling and proposed operating strategies.

\section{Visit to Itasca Consulting}

Prior to this project, but related to the goals of the project, we visited Itasca Consulting (Minneapolis, Minn.) on May 20. Itasca is a well known geotechnical company, with most of their work related to mining. The goal of the meeting was to demonstrate the current Geocrack2D capabilities and, primarily, to focus on the 3D geometric modeling work. Itasca representatives included Peter Cundall and Dave Potyondy. Itasca also demonstrated their present analysis capabilities. The meeting was primarily an exchange of information, especially with respect to the use of topology to describe geometry and approaches to cross-platform development. While more formal future collaboration is possible, the current focus will be exchange of concepts. 


\section{Booth at October GRC Meeting}

A booth has been reserved at the October GRC meeting at which we will display Geocrack2D, the Geocrack3D prototype, and discuss our work at Kansas State University.

\section{National and International Collaboration}

\section{Web Site}

Information and the executable programs for Geocrack2D are available on the world wide web. This quarter, we updated the world wide web page (http://www.engg.ksu.edu/ geocrack) with animated gif's showing cooling of a reservoir and deformation as the rock contracts. This is also the site at which the Geocrack2D software can be downloaded. We now monitor the software downloads (these are the people who actually download the software, not just visit the site). At this time, there is an average of about one download a day from an international mix of addresses.

\section{Collaboration with Proposed Australian HDR Project}

In collaboration with Prame Chopra and Doone Wyborn of the Department of Geology, Australian National University, Geocrack2D calculations are being made of a proposed Australian HDR project.

Australia is unique in that most of the crust in Australia is subject to a crustal shortening stress field, in which the minimum principal stress direction is sub-vertical to vertical in orientation. This means that a reservoir created by stimulation should lie predominantly in a horizontal plane.

Geocrack2D is being used to provide estimates of the performance of such a reservoir. Figure 1 illustrates temperature contours predicted after ten years of operation. The figure shows a vertical plane through the reservoir, with injection in the center and two producing wells at each end of the reservoir. A report and paper documenting the calculations are being prepared. 


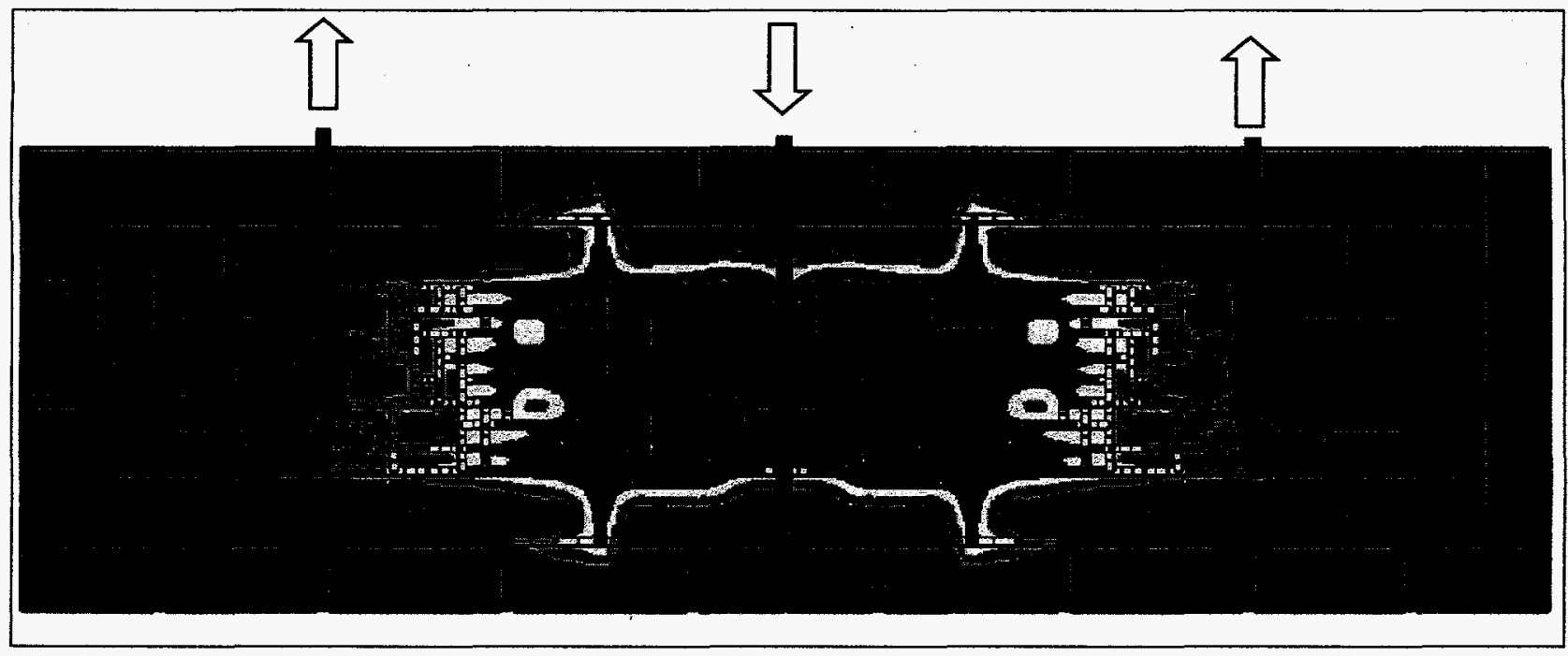

Figure 1: Temperatures after 10 years (Vertical section, including boreholes)

\section{MODEL DEVELOPMENT:}

\section{Geocrack2D Maintenance}

Maintenance of Geocrack2D has included improved font selection for lower resolution displays $(640 \times 480)$. A bug in the contour plots of stresses has also been corrected. The new versions have been posted on the web.

\section{Geocrack3D Development}

Primary effort has been devoted to development of Geocrack3D. The goal of this software is to allow the user to work at the geometry level of a problem, while the details of meshing and solution are handled automatically. What is meant by the "geometry level" is that the user defines the border of a reservoir and then the geometric features (fractures, wellbores) of the model. Working at this level simplifies the task of the analyst and allows easy modification of the model. After the geometry is defined the mesh will be automatically developed. This approach is similar to the work at Kansas State University and Cornell University that is being applied to NASA research on crack growth in aircraft structures.

In order to implement the geometric approach reliably, it is necessary to use topology to describe the relationships between the vertices, edges, faces, and volumes of a model. The development of the Euler operators that accomplish this has been completed. Figure 2 shows an extremely simple application of the operators. This figure demonstrates that the capability to 
add faces, vertices, edges to a non-manifold geometric model has been completed. We are now working on the higher functions that manipulate this basic geometric data.

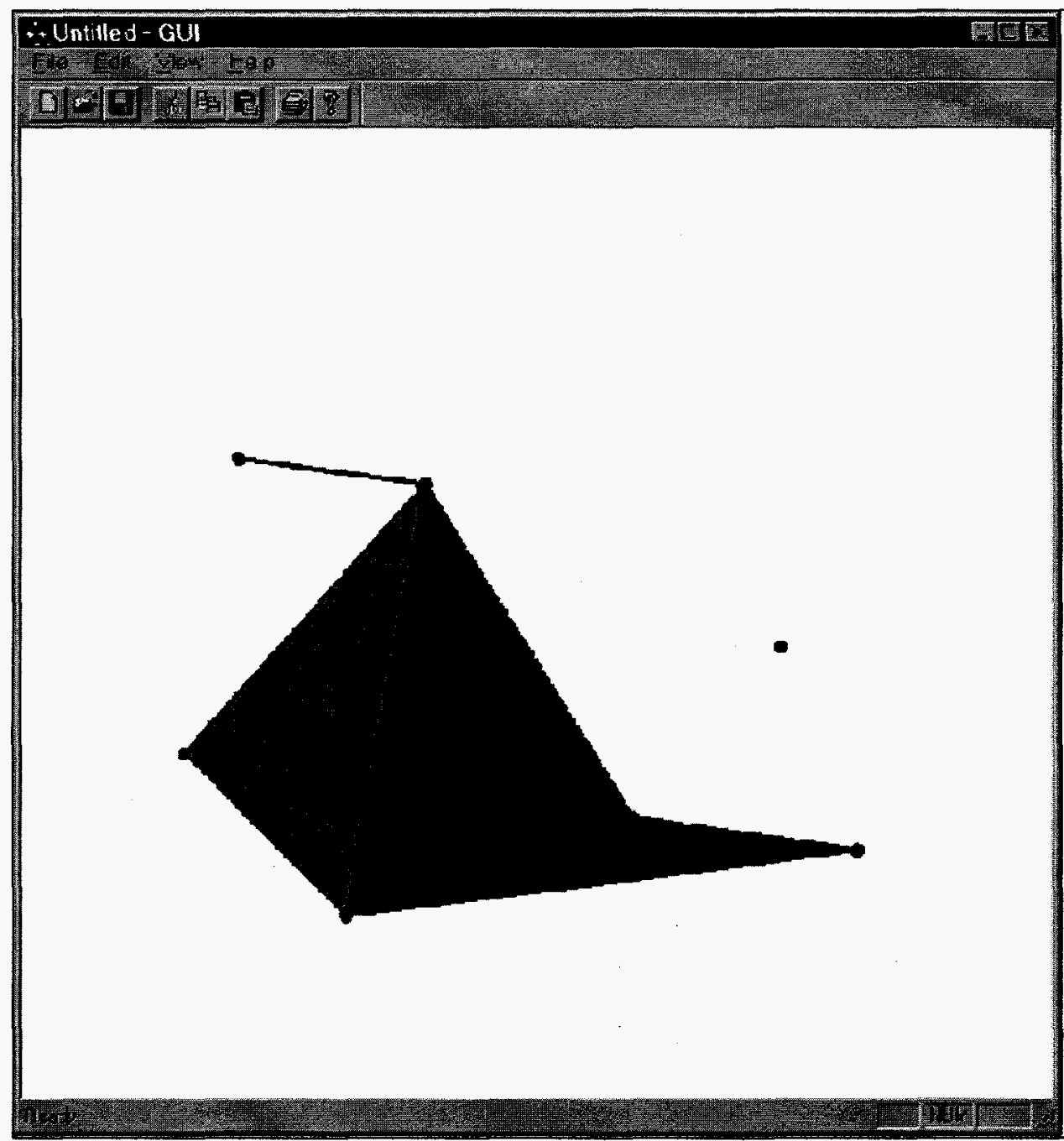

Figure 2: An initial demonstration of geometry description using Euler operators

\section{DISCLAIMER}

This report was prepared as an account of work sponsored by an agency of the United States Government. Neither the United States Government nor any agency thereof, nor any of their employees, makes any warranty, express or implied, or assumes any legal liability or responsibility for the accuracy, completeness, or usefulness of any information, apparatus, product, or process disclosed, or represents that its use would not infringe privately owned rights. Reference herein to any specific commercial product, process, or service by trade name, trademark, manufacturer, or otherwise does not necessarily constitute or imply its endorsement, recommendation, or favoring by the United States Government or any agency thereof. The views and opinions of authors expressed herein do not necessarily state or reflect those of the United States Government or any agency thereof. 